\title{
The canine cognitive dysfunction rating scale (CCDR): A data-driven and ecologically relevant assessment tool
}

\author{
Hannah E. Salvin ${ }^{\text {a,* }}$, Paul D. McGreevy ${ }^{\text {a }}$, Perminder S. Sachdev ${ }^{\text {b,c,d }}$, Michael J. Valenzuela ${ }^{\text {b,d }}$ \\ ${ }^{a}$ Faculty of Veterinary Science (B19), University of Sydney, Camperdown, NSW 2006, Australia \\ ${ }^{\mathrm{b}}$ School of Psychiatry, University of New South Wales, Sydney, Australia \\ ${ }^{\mathrm{c}}$ Neuropsychiatric Institute, Prince of Wales Hospital, Randwick, NSW 2031, Australia \\ ${ }^{\mathrm{d}}$ Brain and Ageing Research Program, Faculty of Medicine, University of New South Wales, Sydney, Australia
}

\section{A R T I C L E I N F O}

\section{Article history:}

Accepted 10 May 2010

\section{Keywords:}

Canine

Cognitive dysfunction

Ageing

Diagnosis

Assessment

\begin{abstract}
A B S T R A C T
Canine cognitive dysfunction (CCD) is an age-related neurobehavioural syndrome which, although common, is severely under-diagnosed in community-based dogs. Using data from a large cross-sectional survey of older dogs $(n=957)$, this study aimed to develop a clinical scale for assessing CCD. Data-driven analytical techniques were used to distil 27 significant behavioural items (previously identified as relevant to $(C D$ ) into an assessment tool with maximal cognito-behavioural breadth whilst maintaining clinical utility. The resulting CCD rating scale (CCDR) comprised 13 behavioural items, of which three were sensitive to the severity of the disease stage.

When tested on an independent survey sample, the CCDR had an overall $98.9 \%$ diagnostic accuracy with a $77.8 \%$ positive predictive value and a $99.3 \%$ negative predictive value. Test-re-test reliability of the CCDR over 2 months was also high $(r=0.73, P<0.0001)$. In conjunction with veterinary assessment, the CCDR could be a valuable tool in research and clinical settings for both the assessment and longitudinal tracking of cognitive change.
\end{abstract}

() 2010 Elsevier Ltd. All rights reserved.

\section{Introduction}

Canine cognitive dysfunction (CCD) or 'canine dementia' is a neurobehavioural syndrome in aged dogs characterized by deficits in learning, memory and spatial awareness, as well as changes to social interactions and sleeping patterns (Landsberg et al., 2003). Whilst several prevalence studies have identified CCD as a common problem in aged dogs (Neilson et al., 2001; Osella et al., 2007; Azkona et al., 2009), our findings in a recent epidemiological survey suggested that the disease was severely under-diagnosed with up to $85 \%$ of potentially affected animals failing to be identified (Salvin et al., 2010).

CCD shares several similarities with human Alzheimer's disease (AD). These include the progressive characteristics of the clinical syndrome, neuropathological abnormalities and pharmacological responsiveness (Ruehl et al., 1995; Cummings et al., 1996; Studzinski et al., 2005). CCD may therefore serve as a useful translational model for $A D$, but the current major limiting factor for both research and community dog health is the absence of an evidencebased tool for assessment and accurate monitoring of clinical progression or response to therapy. Most importantly, delineation of behavioural changes unique to $\mathrm{CCD}$ and in contradistinction to

\footnotetext{
* Corresponding author. Tel.: +61 0410317831.

E-mail addresses: hsal8835@uni.sydney.edu.au,h.salvin@usyd.edu.au (H.E. Salvin).
}

normal canine ageing has been lacking. A number of theory-driven scales and checklists have been proposed with their own unique formulations (Colle et al., 2000; Landsberg et al., 2003; Pugliese et al., 2005), yet the rationale for item selection and scoring has often not been clear.

Recent research has identified 27 behaviours that delineate aged dogs with a cognitive profile consistent with dementia from those exhibiting normal ageing (Salvin et al., 2010). Data-driven analytical techniques were used to group one half of a large cross-sectional dataset into naturalistic groups based on their behavioural differences. Whilst these data provide a useful base, it is important to further refine the behaviours most useful for assessing the cognitive profile of aged dogs into an appropriate clinical assessment tool. In addition, the predictive value of these behaviours needs to be assessed in an independent dataset.

Our aim in this study was to use an independent dataset from a large cross-sectional study of older companion dogs to develop a CCD assessment tool that accurately distinguishes the syndrome from normal ageing.

\section{Materials and methods}

Study design

The senior dog survey (SDS) consisted of an 84 item questionnaire, covering six sections, namely, (1) dog and owner details, (2) management and health, (3) eating 


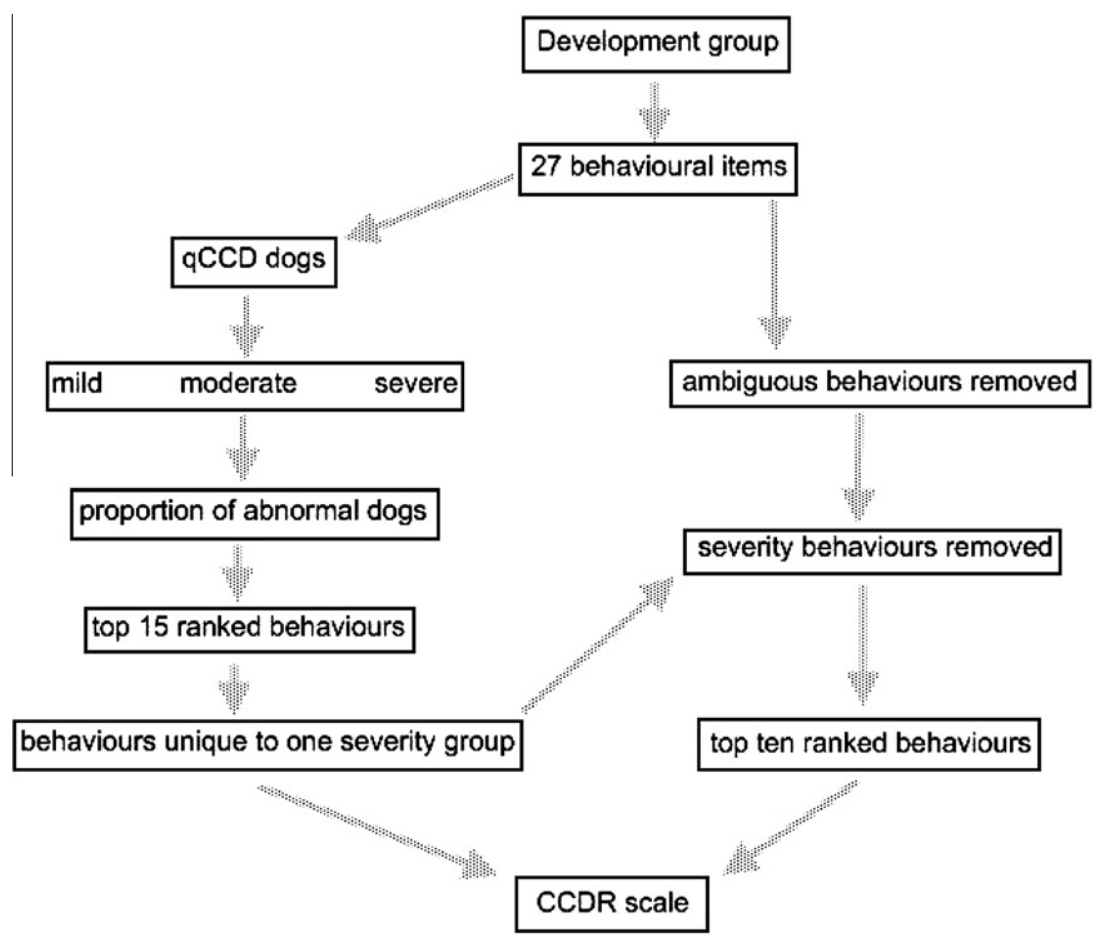

Fig. 1. Methodology of item refinement for CCDR.

and drinking, (4) activity levels, (5) behaviour (including aggression and housesoiling), and (6) phobias. Each item identified both the frequency of a behaviour and the level of change in that behaviour over the preceding 6 months. Questions on behaviour frequency were scored from 1 (least) to 5 (most). Questions on the change in behaviour were also scored 1 (much less) to 5 (much more), with 'no change' being scored as 3 . All missing values were replaced with the mean for that variable.

\section{Study setting and participants}

The survey was distributed in online and hard copy formats and owners of dogs $>8$ years of age were invited to participate. An unlimited number of responses were collected from September 2007 to March 2008. A link to the online version was distributed via a dog forum ${ }^{1}$ and a training website. ${ }^{2}$ The survey link was emailed to staff and students at veterinary colleges in Australia, New Zealand, the United Kingdom and North America. A hard copy version of the survey was published in DogsLife Magazine, $^{3}$ which has an estimated readership of 92000 in Australia and New Zealand. Additional responses from the owners of dogs with diagnosed dementia (DEM) were obtained by approaching all veterinary clinics in the North-west Sydney area $(n=20)$.

\section{Statistical analysis}

SPSS v17 was used and the significance threshold was set at $P=0.05$ for all analysis. The entire survey sample was randomly split into two equal groups: Development $(n=479)$ and Test $(n=478)$. An equal number of veterinary diagnosed CCD/ DEM dogs $(n=9)$ were randomly assigned to each group. In a previous study (Salvin et al., 2010), two-step cluster analysis was used on the Development group to isolate 27 ranked behavioural items that distinguished dogs with no cognitive impairment $(\mathrm{NCI})$ from those with unidentified 'query' $\mathrm{CCD}\left(\mathrm{qCCD}_{27}, n=59\right)$ - i.e. dogs with a behavioural profile similar to DEM dogs. In the current study, the Development group was further used to refine these 27 behaviours into an assessment tool. An independent Test group was then used to rule out the possibility that the preceding exploratory techniques had taken advantage of sample specific itemdiagnostic contingencies, and hence artificially inflated accuracy estimates.

\footnotetext{
1 See: www.dogzonline.com.au.

2 See: www.apdt.com.au.

${ }^{3}$ Universal Magazines (North Ryde NSW Australia), Issue 86, November/December 2007.
}

Item selection

The 27 behaviours were further refined to a subset of $n$ number of items intended to provide clinical utility whilst still retaining cognito-behavioural breadth (Fig. 1).

For severity-sensitive items, $\mathrm{qCCD}_{27}$ dogs were split into three equal groups, namely, mild, moderate and severe based on their summed behavioural score of the 27 behavioural items. In each severity group, the proportion of $\mathrm{qCCD}_{27}$ dogs that scored as 'abnormal' on each item was calculated. For most items, 'abnormal' was defined as positive evidence of an index behaviour (in contrast to not performing that behaviour at all), or for change related questions, an increased frequency in that behaviour within the previous 6 months. For the remaining items: abnormal time taken to learn was specified as 'greater than 3-5 attempts'; abnormal waking at night was specified as 'more than 1-5 times' and; abnormal response to commands was specified as 'less than $60-90 \%$ of the time'.

Behavioural items in each severity group were then ranked according to the proportion of $\mathrm{qCCD}_{27}$ dogs defined as 'abnormal' for that item. Items in the top 15 ranked behaviours which were unique to a single severity group were identified and segregated from the remaining behaviours. This process therefore identified items that were maximally representative for the mild, moderate and severe disease stages.

Items for which respondents reported any difficulty in answering were removed from the analysis. Both the questions on frequency and change in that behavioural item were removed if present.

From the original cluster ranking, the top 10 behavioural items were then selected. These, in addition to the severity-sensitive items, formed the canine cognitive dysfunction rating scale (CCDR). Severity items were weighted $\mathrm{x} 1$ for mild, $\mathrm{x} 2$ for moderate and $\mathrm{x} 3$ for severe.

\section{Diagnostic accuracy}

The threshold for normal ageing ( $\mathrm{NCI}$ ) was set at the summed CCDR behavioural score of the lowest ranking DEM dog. All dogs which scored on or above this were classified as qCCD dogs and excluded from the analysis. Discriminate analysis was then used to determine the diagnostic accuracy of the CCDR scale in distinguishing between $\mathrm{NCI}$ and DEM dogs. In addition, discriminate analysis was also used to validate the accuracy of the CCDR scale in the independent Test group.

\section{Psychometric analysis}

Classical and non-classical test theories were used to investigate the psychometric properties of the CCDR scale. Cronbach's $\alpha$ was used to estimate the internal coherence of the items by calculating the average correlation coefficient between all 
possible item pairs. Factor analysis was then used to test the assumption that a single principle factor could be used to explain the majority of the variance and that secondary factors would have only a minor effect.

Item response theory (IRT) is a non-classical method for testing the relationship between an individual respondent's performance on a particular scale item and the severity of signs in the underlying variable of interest (in this case CCD). IRT relies on the underlying assumption that individuals with a high CCD severity will have a higher probability of responding positively to relevant scale items. TestGraf is an IRT graphical modelling software (Ramsey, 2000) that was used to convert the ranked sum CCDR score of all respondents into a standard normal score and then to use this as a metric for the underlying trait. The advantage of IRT over classical test theories is that it does not assume a fixed item performance-trait relationship and it produces unbiased item characteristic curves and reliability plots across all underlying CCD levels.

Finally, test-re-test reliability was determined by providing a link to the CCDR scale in an online dog forum ${ }^{4}$ and asking 104 of the NCI dog owners that responded to complete the CCDR a second time 3 weeks later. To reduce any bias towards increased observation of their dogs, respondents were not told of the possibility of a re-test.

\section{Results}

Senior dog survey

A total of 1100 responses were obtained of which 957 were eligible for inclusion. Eligible responses were obtained from 11 countries, predominantly Australia $(n=501)$, the United States $(n=342)$, New Zealand $(n=51)$ and the UK $(n=41)$. Eligible responses $(n=842)$ were obtained via the online version of the survey, 111 eligible responses were returned through DogsLife magazine and four eligible responses were obtained through veterinary practices. The average proportion of missing values across all variables was low (1.3\%).

In the complete sample, 18 dogs were reported as having a formal diagnosis of 'dementia' or CCD by a veterinarian (DEM). DEM dogs (13 years 8 months) were significantly older than non-DEM dogs (11 years 8 months, $P=0.004$ ).

\section{Sample characteristics}

The mean age of surveyed dogs was 11 years 9 months (range: 8 years-19 years 8 months). There were 109 different pedigree breeds and 203 crossbred dogs represented. Female dogs (54.8\%) slightly outnumbered male dogs (44.6\%). The majority of dogs were neutered: $84.3 \%$ of males and $94.1 \%$ of females. On several key basic descriptive criteria (age, sex, disease burden), there were no systematic differences between the Development and Test groups.

\section{Severity-sensitive items}

Of the top 15 ranked behaviours in each severity group, one behaviour from each group was unique to that severity. 'Avoiding contact or petting' was unique to the mild group, 'change in difficulty finding dropped food' was unique to the moderate group and 'change in recognition of owners' was unique to the severe group. The proportion of 'abnormal' dogs for each of these behaviours across severity groups is shown in Fig. 2.

\section{Ambiguous items}

Based on comments made by respondents, five behavioural items of the original 27 were excluded. Table 1 gives examples of the type of comments made and the proportion of respondents that left that item blank. The remaining 22 behaviours were ranked according to the original cluster analysis levels of significance. (a)

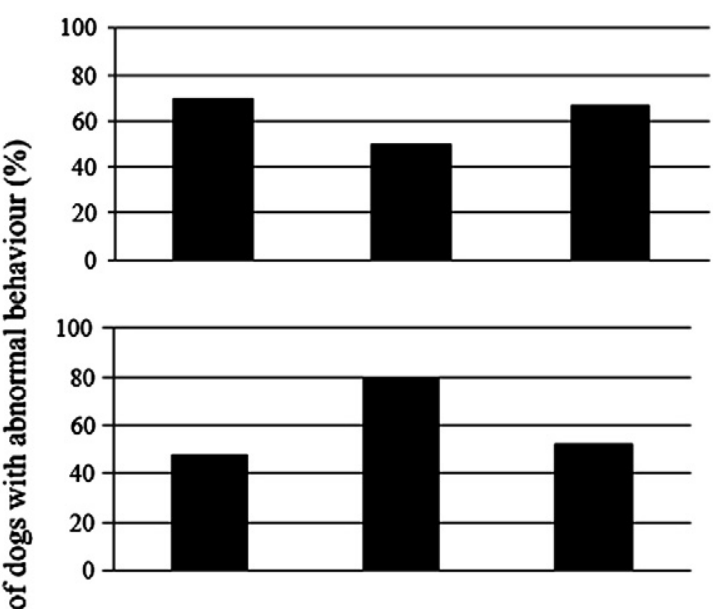

(c)

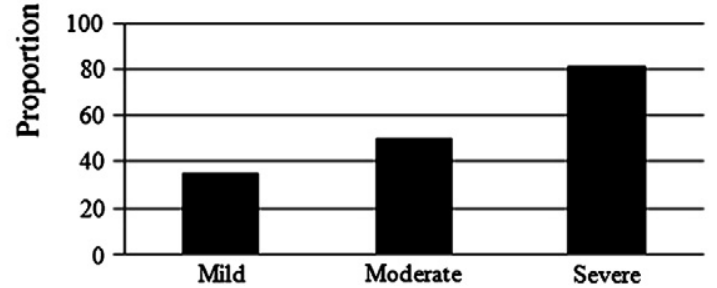

Fig. 2. Percentage of abnormal dogs across severity groups; mild, moderate and severe: (a) avoids contact or petting, unique to top 15 ranked items for mild group; (b) change in difficulty finding dropped food, unique to top 15 ranked items for moderate group; (c) change in recognition of owners, unique to top 15 ranked items for severe group.

\section{The CCDR scale}

The three severity-sensitive items with their respective weightings and the top 10 cluster-ranked items comprise the 13-item CCDR scale. Details of items, scoring and exemplary data are presented in Table 2 . The mean sum of behavioural scores on the CCDR was 62 for DEM dogs (range 50-75) and 40 for non-DEM dogs (range 32-76). The optimal diagnostic threshold for qCCD was therefore set at a summed CCDR score of 50 or above, equivalent to the lowest score for a veterinarian-confirmed DEM dog.

\section{Table 1}

Examples of comments from respondents reporting a difficulty in answering an item and the percentage of missing values for that item (average percentage of missing values for all items $=1.3 \%$ ) Only items within the 27 behaviours of interest are reported here.

\begin{tabular}{|c|c|c|}
\hline Item & $\begin{array}{l}\text { Missing } \\
\text { values }\end{array}$ & Example of comments \\
\hline $\begin{array}{l}\text { Time taken to learn new } \\
\text { tasks } \\
\text { Frequency only }\end{array}$ & $9.5 \%$ & $\begin{array}{l}\text { I do not try to teach him/her } \\
\text { anything new } \\
\text { Meets very few new tasks } \\
\text { Depends on the difficulty of task }\end{array}$ \\
\hline Excitement for walks & $\begin{array}{l}1.6 \% \\
\text { (frequency) }\end{array}$ & No walks given \\
\hline Frequency and change & $\begin{array}{l}1.5 \% \\
\text { (change) }\end{array}$ & $\begin{array}{l}\text { Goes for car rides instead } \\
\text { Is not excited if its raining } \\
\text { Live on acreage so walks itself } \\
\text { Is on exercise restrictions due to } \\
\text { health }\end{array}$ \\
\hline Response to commands & $\begin{array}{l}3.1 \% \\
\text { (frequency) }\end{array}$ & Is deaf so does not respond \\
\hline Frequency and change & $\begin{array}{l}2.1 \% \\
\text { (change) }\end{array}$ & $\begin{array}{l}\text { Did not train the dog properly as a } \\
\text { puppy } \\
\text { Depends if we have food }\end{array}$ \\
\hline
\end{tabular}




\section{Discriminate analysis}

Using this CCDR threshold, 57 (11.9\%) dogs were classified as qCCD and excluded from further analysis. The 13 CCDR items were successfully able to distinguish between NCI and DEM dogs; in the Development group, overall diagnostic accuracy was $99.8 \%$ with positive (PPV) and negative (NPV) predictive values of $88.9 \%$ and $100 \%$ respectively. When assessed in the independent Test group, the overall diagnostic accuracy remained high at $98.9 \%$ (PPV = 77.8\%; NPV = 99.3\%).

\section{Psychometric properties}

The CCD items showed a high level of coherence with a Cronbach's $\alpha$ of 0.86 . Deletion of any one item had minimal effect on coherence, with the change in $\alpha$ ranging from 0 to 0.019 . Factor analysis identified a single major underlying component that accounted for $41.4 \%$ of the total variation. For the second, third and fourth components, the proportion of variance explained dropped to $8.9 \%, 7.9 \%$ and $7.2 \%$, respectively.

Characteristic curves were generated for each item using IRT analysis. For each item, the curves showed an almost linear increase in the probability of scoring highly on that item as the standardised score for the underlying CCD trait increased. An example of an item characteristic curve for one behavioural item is shown in Fig. 3. Characteristic curve graphs for all 13 CCDR items can be viewed in online Supplementary material.

Fig. 4 shows the polynomial reliability distribution for the CCDR. Peak reliability occurs in the high trait severity range $(\sim 0.92)$ with the least reliability being shown in the mid range $(\sim 0.765)$.

Of the 104 respondents who completed the CCDR online, 41 returned a second response approximately 3 weeks later giving a response rate of $39.4 \%$. Dogs had an average age of 11 years, 2 months (8-17 years) with an average first CCDR score of 36 (33-48). The average difference between test and re-test scores was $0.17(\mathrm{SD}=2.3$, range -5 to 9$)$. The intraclass correlation coefficient was significant $(r=0.73$, absolute difference method, $P<0.0001)$.

\section{Estimated prevalence}

The prevalence of CCD in the entire SDS cohort (Development and Test groups) was estimated at $12.0 \%$ (115/957). Rates of CCD were similar in males (entire $13.6 \%$; neutered $10.8 \%$ ) and females (entire 9.7\%; neutered 12.7\%). Prevalence also increased exponentially with age $>10$ years with $4.4 \%$ of $8-10$ year-olds; $3.4 \%$ of $10-12$ year-olds; $18.6 \%$ of $12-14$ year-olds and; $31 \%$ of dogs $>14$ years affected.

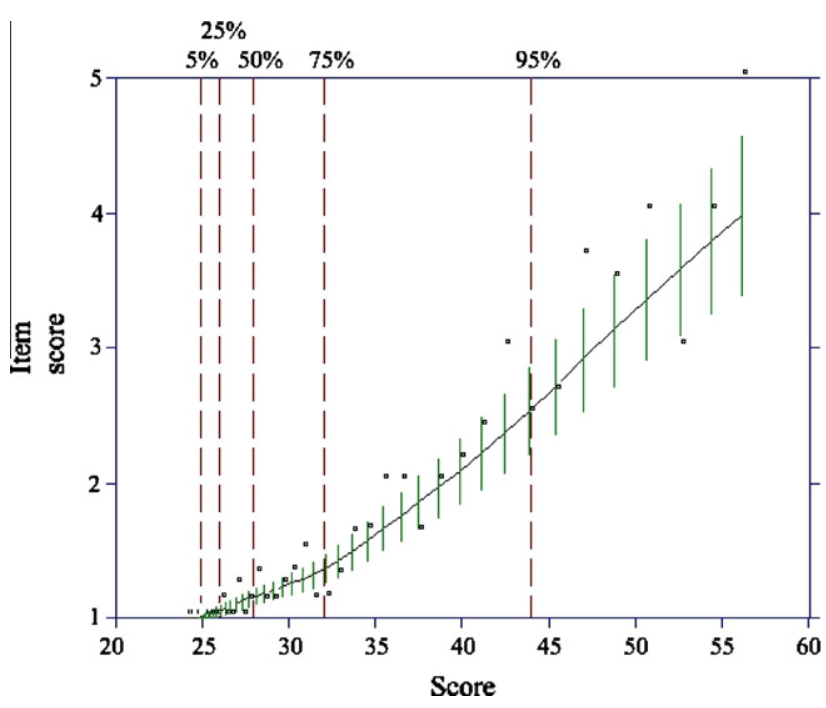

Fig. 3. Item characteristic curve for the behaviour 'gets stuck behind objects and is unable to get around'. The probability of a dogs scoring highly on this behaviour increases with increasing underlying trait scores.

Table 2

Canine cognitive dysfunction rating scale with example data for a dog over the threshold $(\geqslant 50)$ for query diagnosis.

\begin{tabular}{|c|c|c|c|c|c|c|c|}
\hline & $\begin{array}{l}(1) \\
\text { Never }\end{array}$ & $\begin{array}{l}(2) \\
\text { Once a } \\
\text { month }\end{array}$ & $\begin{array}{l}(3) \\
\text { Once a } \\
\text { week }\end{array}$ & $\begin{array}{l}(4) \\
\text { Once a } \\
\text { day }\end{array}$ & $\begin{array}{l}(5) \\
>\text { Once } \\
\text { a day }\end{array}$ & & Score \\
\hline $\begin{array}{l}\text { How often does your dog pace up and down, walk in circles and/or wander with no direction or } \\
\text { purpose? }\end{array}$ & & & & $\mathrm{X}$ & & & 4 \\
\hline How often does your dog stare blankly at the walls or floor? & & & $\mathrm{X}$ & & & & 3 \\
\hline How often does your dog get stuck behind objects and is unable to get around? & $\mathrm{X}$ & & & & & & 1 \\
\hline How often does your dog fail to recognise familiar people or pets? & & & & $\mathrm{X}$ & & & 4 \\
\hline How often does your dog walk into walls or doors? & & $\mathrm{X}$ & & & & & 2 \\
\hline \multirow[t]{2}{*}{ How often does your dog walk away while, or avoid, being patted? } & & & $\mathrm{X}$ & & & & 3 \\
\hline & Never & $\begin{array}{l}1-30 \% \text { of } \\
\text { times }\end{array}$ & $\begin{array}{l}31-60 \% \\
\text { of times }\end{array}$ & $\begin{array}{l}61-99 \% \\
\text { of times }\end{array}$ & Always & & \\
\hline \multirow[t]{2}{*}{ How often does your dog have difficulty finding food dropped on the floor? } & & & & $\mathrm{X}$ & & & 4 \\
\hline & $\begin{array}{l}\text { Much } \\
\text { less }\end{array}$ & $\begin{array}{l}\text { Slightly } \\
\text { less }\end{array}$ & The same & $\begin{array}{l}\text { Slightly } \\
\text { more }\end{array}$ & $\begin{array}{l}\text { Much } \\
\text { more }\end{array}$ & & \\
\hline $\begin{array}{l}\text { Compared with } 6 \text { months ago, does your dog now pace up and down, walk in circles and/or } \\
\text { wander with no direction or purpose }\end{array}$ & & & & & $\mathrm{X}$ & & 5 \\
\hline Compared with 6 months ago, does your dog now stare blankly at the walls or floor & & & $\mathrm{X}$ & & & & 3 \\
\hline $\begin{array}{l}\text { Compared with } 6 \text { months ago, does your dog urinate or defecate in an area it has previously kept } \\
\text { clean (if your dog has never house-soiled, tick 'the same') }\end{array}$ & & & & $\mathrm{X}$ & & & 4 \\
\hline Compared with 6 months ago, does your dog have difficulty finding food dropped on the floor & & & & $\mathrm{X}$ & & $\mathrm{x} 2$ & 8 \\
\hline \multirow[t]{2}{*}{ Compare with 6 months ago, does your dog fail to recognise familiar people or pets } & & & & & $\mathrm{X}$ & $\mathrm{x} 3$ & 15 \\
\hline & $\begin{array}{l}\text { Much } \\
\text { more }\end{array}$ & $\begin{array}{l}\text { Slightly } \\
\text { more }\end{array}$ & The same & $\begin{array}{l}\text { Slightly } \\
\text { less }\end{array}$ & $\begin{array}{l}\text { Much } \\
\text { less }\end{array}$ & & \\
\hline \multirow[t]{2}{*}{ Compared with 6 months ago, is the amount of time your dog spends active } & & & & $\mathrm{X}$ & & & 4 \\
\hline & & & & & Total & & 60 \\
\hline
\end{tabular}




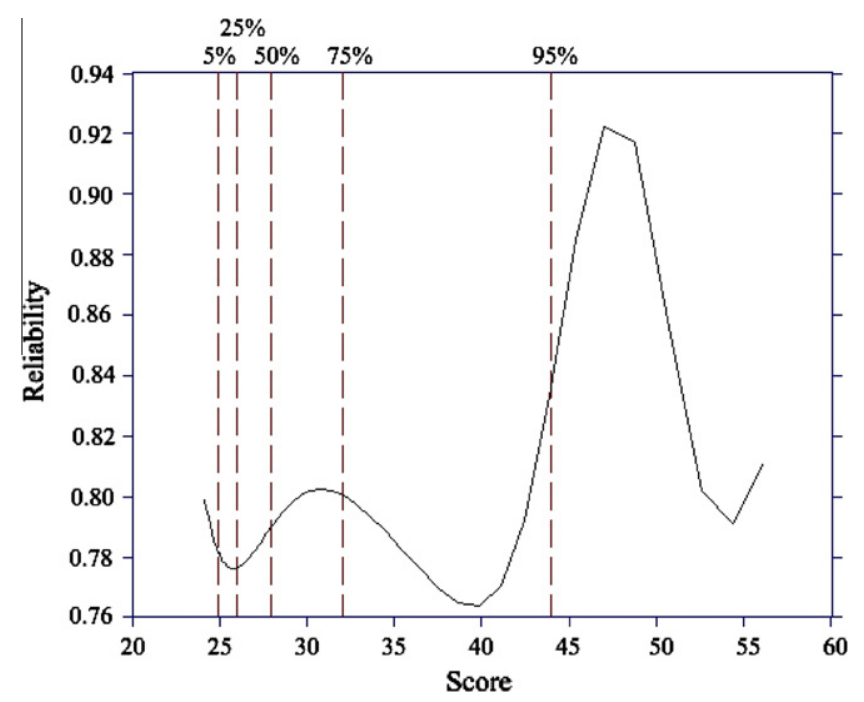

Fig. 4. Reliability function for the canine cognitive dysfunction rating scale, calculated using an item response theory approach, showing peak reliability in the high range of underlying trait scores, moderate reliability in the low scores and lower reliability in the mid scores. Despite polynomial variation in reliability estimates, reliability remains high, above 0.76 across all trait scores.

\section{Discussion}

CCD is a highly prevalent yet severely under-diagnosed disease affecting a growing population of aged dogs. There is a common misconception amongst owners that the onset of neurobehavioural disturbance late in a dog's life is a normal part of ageing, leading to low presentation rates (Landsberg and Araujo, 2005). Conversely, the lack of clear diagnostic guidelines for CCD has meant that bona fide normative age-related changes, which occur in all mammals, are sometimes interpreted as part of a neurodegenerative process. Previous CCD scales have essentially been derived from clinical experience, have lacked psychometric validation, and are not widely used. The current large-scale epidemiological survey of owners used unbiased and data-driven methods to clarify normal versus abnormal age-related neurobehavioural change in older dogs to develop a practical clinical assessment tool.

Our analysis isolated a cluster of 13 behaviours that, when abnormal, agreed with veterinary diagnosis of canine dementia almost $80 \%$ of the time. These 13 behaviours were used to form the CCD Rating scale (CCDR), which focuses on problems related to orientation (staring blankly, getting lost in the home), memory (lack of recognition of owners, house-soiling), apathy (reduced time spent active, avoiding contact with owners), impaired olfaction (difficulty finding food) and locomotion. These problem areas resemble many of the different stages of human $\mathrm{AD}$ dementia (Hughes et al., 1982; Swan and Carmelli, 2002), and compromise both the dog's quality of life and the dog-owner bond.

Classical test theories and IRT analysis were used to further investigate the psychometric properties of the CCDR scale. Reliability peaked at 0.9 at the high trait severity level, suggesting that the CCDR is most reliable when behavioural disturbances are severe. This is consistent with the aim of our scale, which is to identify those dogs with CCD rather than distinguish between dogs in the normal range of the behavioural spectrum. Each item in the CCDR was also found to have appropriate response characteristics. Option characteristic curve analysis for each individual item showed that, as the underlying CCD trait increased, there was an appropriate linear increase in the probability of dog owners choosing a higher response option. Furthermore, factor analysis showed the strong presence of a single and dominant underlying factor, indi- cating that the CCDR does indeed estimate a unitary construct. Finally, test-re-test analysis found that the scale is highly stable when completed several weeks apart. On average, scores deviated by less than $1 \%$. These data therefore suggest that the CCDR provides a valid and psychometrically robust assessment of CCD in older companion dogs.

Scores $>50$ on the CCDR are indicative of CCD in older companion dogs. However, like for human dementia, transient and reversible causes of behavioural changes need to be excluded prior to making a definitive diagnosis. CCDR scores by themselves are therefore essentially a screening tool to allow the veterinarian to assess the level of cognitive decline in an individual. The combination of a CCDR score $>50$ and veterinary assessment is proposed as a definitive and standardised method of diagnosing CCD in veterinary practice. Given the high level of agreement between test and re-test administration, longitudinal change in CCDR scores $>4$ points, or more than two standard deviations, is behaviourally significant when made by the same primary carer. In this way, the CCDR may prove useful for assessing disease progression and therapeutic response in both clinical and research settings.

A limitation of this study was the relatively low number of reported DEM dogs, leading to the possibility that these animals were not representative of the true CCD profile. Nevertheless, our study remains the largest epidemiological study of ageing dogs to date. We also observed similarities between many of the items that comprise the CCDR as a result of mainly a data-driven approach, and those derived from purely clinical CCD descriptions (Ruehl et al., 1995; Landsberg et al., 2003). Interestingly, we also identified some new behavioural changes that are central to the CCD syndrome, including difficulty finding food dropped on the floor and avoiding being petted. An important next step will be to use the CCDR in prospective studies that assess the tool's ability to identify and assess CCD dogs in a clinical setting.

On a clinical level, the CCDR has several implications since it may help to address the current under-diagnosis and mismanagement of CCD. Current pharmaceutical and nutraceutical options include selegiline, a monoamine oxidase B inhibitor and the dietary supplements L-Carnitine and Omega-3 fatty acids. Evidence also exists for the benefits of Vitamins $E$ and $C$ and antioxidants in the diet (Landsberg, 2005). All of these treatment options have increased efficacy if applied very early in the disease progression or as a prophylactic.

By raising awareness of cognitive ageing and providing a valid method for assessing a dog's level of cognitive decline, the CCDR will allow veterinarians to better determine the appropriate time to initiate treatment. Alternatively, a standardised assessment of the level of decline may aid owners in making the decision to euthanase before the disease progresses further. Overall, animal welfare could be enhanced by early diagnosis and care, costs could be relieved by treatment of early symptoms, and the quality of the dog-owner bond could be conserved for longer. Finally, development of the CCDR scale is expected to further stimulate research of CCD in companion (rather than laboratory) dogs as a naturalistic and ecologically valid model of AD dementia and aid in the development and assessment of novel treatment options in both species.

\section{Conclusions}

The CCDR scale presented here is a clinically and ethologically relevant screening and assessment tool. In conjunction with veterinary assessment, it can distinguish those neurobehavioural changes associated with cognitive dysfunction from normal ageing. The CCDR had a high diagnostic accuracy (99.3\%) and favourable psychometric properties. Use of the CCDR scale in research and clinical settings could advance canine and human health. 


\section{Conflict of interest statement}

None of the authors of this paper has a financial or personal relationship with other people or organisations that could inappropriately influence or bias the content of the paper.

\section{Acknowledgements}

This work was funded by NHMRC Program Grant 350833. The study sponsors had no involvement in the study design; collection, analysis and interpretation of data; writing of the manuscript; or the decision to submit this manuscript for publication. We thank Dr. Bill Milgram for his expert comments on a previous version of this manuscript, which improved this work. Thanks to DogsLife magazine for publishing the Senior Dog Survey in their 86th issue. We also appreciate the support of the following institutions for assisting in the distribution of the online survey: University of Pennsylvania; Massey University; University of Melbourne; University of Sydney; Murdoch University; University of Edinburgh; University of Nottingham; New England Institute of TAFE; University of Wisconsin-Madison; Oregon State University; Association of Pet Dog Trainers (Australia) and Dogzonline.

\section{Appendix A. Supplementary material}

Supplementary data associated with this article can be found, in the online version, at doi:10.1016/j.tvjl.2010.05.014.

\section{References}

Azkona, G., García-Belenguer, S., Chacón, G., Rosado, B., León, M., Palacio, J., 2009. Prevalence and risk factors of behavioural changes associated with age related cognitive impairment in geriatric dogs. Journal of Small Animal Practice 50, 87-91.

Colle, M.-A., Hauw, J.-J., Crespeau, F., Uchihara, T., Akiyama, H., Checler, F., Pageat, P., Duykaerts, C., 2000. Vascular and parenchymal Ab deposition in the aging dog: correlation with behaviour. Neurobiology of Aging 21, 695-704.
Cummings, B.J., Head, E., Ruehl, W., Milgram, N.W., Cotman, C.W., 1996. The canine as an animal model of human aging and dementia. Neurobiology of Aging 17, 259-268.

Hughes, C.P., Berg, L., Danziger, W.L., Coben, L.A., Martin, R.L., 1982. A new clinical scale for the staging of dementia. The British Journal of Psychiatry 140, 566-572.

Landsberg, G., Hunthausen, W., Ackerman, L., 2003. The effects of aging on the behaviour of senior pets. In: Landsberg, G., Hunthausen, W., Ackerman, L. (Eds.), Handbook of Behaviour Problems of the Dog and Cat, second ed. Saunders, Edinburgh, UK, pp. 269-304.

Landsberg, G., 2005. Therapeutic agents for the treatment of cognitive dysfunction syndrome in senior dogs. Progress in Neuro-Psychopharmacology and Biological Psychiatry 29, 471-479.

Landsberg, G., Araujo, J.A., 2005. Behaviour problems in geriatric pets. Veterinary Clinics Small Animal Practice 35, 675-698.

Neilson, J.C., Hart, B.J., Cliff, K.D., Ruehl, W., 2001. Prevalence of behavioural changes associated with age-related cognitive impairment in dogs. Journal of the American Veterinary Medical Association 218, 1787-1791.

Osella, M.C., Re, G., Odore, R., Girardi, C., Badino, P., Barbero, R., Bergamasco, L., 2007. Canine cognitive dysfunction syndrome: prevalence, clinical signs and treatment with a neuroprotective nutraceutical. Applied Animal Behaviour Science 105, 297-310.

Pugliese, M., Carrasco, J.L., Andrade, C., Mas, E., Mascort, J., Mahy, N., 2005. Severe cognitive impairment correlates with higher cerebrospinal fluid levels of lactate and pyruvate in a canine model of senile dementia. Progress in NeuroPsychopharmacology and Biological Psychiatry 29, 603-610.

Ramsey, J., 2000. TestGraf: a program for the graphical analysis of multiple choice test and questionnaire data. Software manual. <http://www.psych.mcgill.ca/ faculty/ramsay/TestGraf.html>.

Ruehl, W., Bruyette, D.S., DePaoli, A., Cotman, C.W., Head, E., Milgram, N.W. Cummings, B.J., 1995. Canine cognitive dysfunction as a model for human agerelated cognitive decline, dementia and Alzheimer's disease: clinical presentation, cognitive testing, pathology and response to 1-depreny therapy. In: Yu, P.M., Tipton, K.F., Boulton, A.A. (Eds.), Progress in Brain Research. Elsevier Science BV, pp. 217-225.

Salvin, H.E., McGreevy, P.D., Sachdev, P.S., Valenzuela, M.J., 2010. Underdiagnosis of canine cognitive dysfunction: a cross-sectional survey of older companion dogs. The Veterinary Journal 184, 277-281.

Studzinski, C.M., Araujo, J.A., Milgram, N.W., 2005. The canine model of human cognitive aging and dementia: pharmacological validity of the model for assessment of human cognitive-enhancing drugs. Progress in NeuroPsychopharmacology and Biological Psychiatry 29, 489-498.

Swan, G.E., Carmelli, D., 2002. Impaired olfaction predicts cognitive decline in nondemented older adults. Neuroepidemiology 21, 58-67. 